\title{
BREASTFEEDING AS A PROTECTIVE FACTOR OF CHRONIC PAIN AFTER CESAREAN. PRELIMINARY PROSPECTIVE COHORT STUDY.
}

Vargas Berenjeno C.A, Sánchez Brotons M.J, Echevarría Moreno M, Trinidad Martín-Arroyo R, Flor Parra F. Nuestra Señora de Valme University Hospital.

Department of Anaesthesiology and Pain Medicine.

Seville, Spain.

\section{BACKGROUND AND GOAL OF STUDY}

Chronic post-cesarean pain (CPCP) has an incidence around $18 \%$ of mothers. In a previous study, we observed an incidence of CPCP around $12 \%$ and that breastfeeding could be a protective factor of chronic pain. The goal of this study is to analyze if breastfeeding really has a protective effect in the incidence of CPCP.

\section{MATERIALS AND METHODS}

Preliminary prospective cohort study

1. Informed consent

2. Structural and presencial interview with mothers in the first 24 and $72 \mathrm{~h}$ after cesarean

3. Telephone interview 4 months after surgery

Main variable: $\mathrm{CPCP}(\mathrm{NSV} \geq 5)$

Main independent variable: Breastfeeding

Others variables

$72 \mathrm{~h}$

- Demographic and sociocultural data

- Surgical techique and number of previous cesareans

- Pain in the first 24-72h

\section{MONTHS}

- Pain in the surgical wound

- About breastfeeding:

- Duration of breastfeeding

- Mixed breastfeeding?

- Anxiety during breastfeeding?

U de Mannwhitney and Chi-cuadrado

Significant $P$ value $(<0,05)$

RESULTS

\section{MOTHERS}

- $94,1 \%$ Pfannestiel tecnique

- $70,1 \%$ skin-to-skin contact with their newborns

- $49,7 \%$ working out of home

- $38,4 \%$ University studies

CPCP: $11,4 \%$ $10 \%$ oral analgesics
CPCP $11,4 \%$

$87 \%$ Breastfeeding

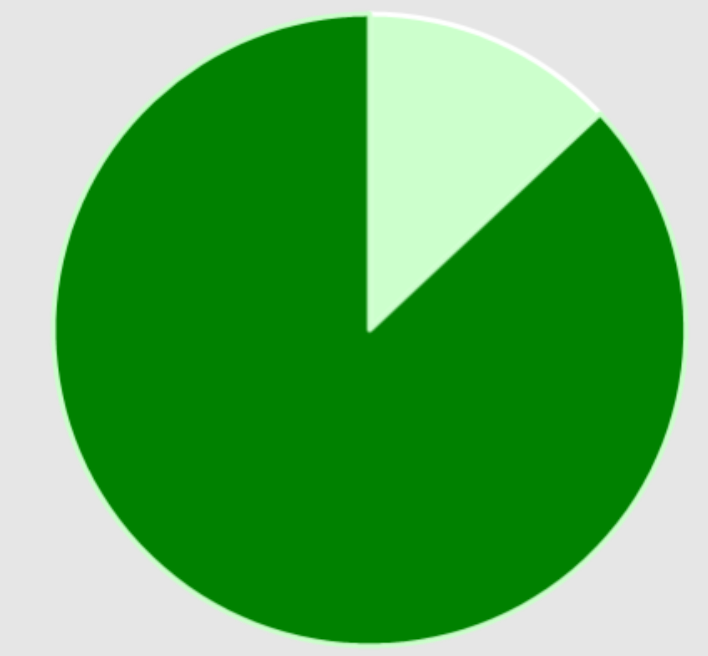

$58,4 \%>2$ months $31,4 \%$ Only breastfeeding $53,8 \%$ Anxiety

\begin{tabular}{c|c|c|c|} 
& Analgesia & NVE & $p=0,0001$ \\
\hline $24 \mathrm{~h}$ & $93,4 \%$ iv & $7^{*}$ & OR $=2$ \\
$72 \mathrm{~h}$ & $41 \%$ iv & 5 & Cl $95 \%(1-2)$
\end{tabular}

\section{DCPC \\ Breastfeeding \\ $p=0,014$ \\ $\mathrm{OR}=3,2$} $>2$ months

$8,3 \%$ $\leq 2$ months

$22,8 \%$

DCPC

Anxiety

$17,3 \%$
DCPC

NO Anxiety

$p=0,159$
Cl 95\% (1.260- 8.224)

$8,8 \%$

\section{CONCLUSIONS}

Preliminary results suggest that breastfeeding for more than 2 months protects against the CPCP in a statistically significant way with a risk three-fold increase in CPCP if breastfeeding is maintained for only 2 months or less. Further, the anxiety during breastfeeding and also mixed breastfeeding, could influence the appearance of pain in the surgical wound 4 months after cesarean. 